\title{
Katı Atık Kullanımına Estetik Bir Çözüm Önerisi: Adıyaman İlindeki Mermer Atıklarından Antik Mozaik Üretimi
}

\author{
Yaprak Tanrıverdi ${ }^{*}$, Erhan Akça ${ }^{2}$, Sabahattin Ezer ${ }^{3}$, Osman Dolaş ${ }^{4}$, Hülya Ak$^{5}$, Tanju Teker ${ }^{6}$ \\ 1* Adıyaman Üniversitesi, Teknik Bilimler Meslek Yüksekokulu, El Sanatları Bölümü, Adıyaman, Türkiye, (ORCID: 0000-0003-3527-5162), \\ yapraktanriverdi@gmail.com \\ ${ }^{2}$ Adıyaman Üniversitesi, Teknik Bilimler Meslek Yüksekokulu, El Sanatları Bölümü, Adıyaman, Türkiye (ORCID: 0000-0001-8988-4196), eakca@ adiyaman.edu.tr \\ ${ }^{3}$ Adıyaman Üniversitesi, Fen Edebiyat Fakültesi, Arkeoloji Bölümü, Adıyaman, Türkiye (ORCID: 0000-0002-9244-5802), sabahattinezer@ yahoo.com \\ ${ }^{4}$ Adıyaman Üniversitesi, Teknik Bilimler Meslek Yüksekokulu, El Sanatları Bölümü, Adıyaman, Türkiye (ORCID: 0000-0002-2979-636X), osmandolas@ gmail.com \\ ${ }^{5}$ Adıyaman Üniversitesi, Teknik Bilimler Meslek Yüksekokulu, El Sanatları Bölümü, Adıyaman, Türkiye (ORCID: 0000-0002-4778-3095), hak@adiyaman.edu.tr \\ ${ }^{6}$ Sivas Cumhuriyet Üniversitesi, Teknoloji Fakültesi, İmalat Mühendisliği Bölümü, Sivas, Türkiye (ORCID: 0000-0001-7293-0723), tanjuteker@cumhuriyet.edu.tr
}

(İlk Geliş Tarihi 18 Kasım 2020 ve Kabul Tarihi 10 Eylül 2021)

(DOI: $10.31590 /$ ejosat.827241)

ATIF/REFERENCE: Tanrıverdi, Y., Akça, E., Ezer, S., Dolaş, O., Ak, H. \& Teker, T. (2021). Katı Atık Kullanımına Estetik Bir Çözüm Önerisi: Adıyaman İlindeki Mermer Atıklarından Antik Mozaik Üretimi. Avrupa Bilim ve Teknoloji Dergisi, (27), 407-411.

Öz

Günümüzde küresel boyutta doğal kaynak kullanımı sonucu ciddi düzeyde atık materyal açığa çıkmaktadır. Özellikle biyolojik olarak ayrıştırılamayan mermer ve granit benzeri katı atıklar çevresel sorunlara yol açmaktadır. Bu materyallerin yeniden kullanımı ekonomiye katma değer katması kadar çevre kirliliğinin önlenmesi için çözümcü bir yaklaşım olarak değerlendirilmelidir. Türkiye blok mermer ihracatında dünyada ön sıralarda yer almaktadır. Blok mermer üretimi ortalama \%5-10 verimle gerçekleştiğinden pasa olarak adlandırılan atık mermerin depolanması önemli çevre sorunlarına yol açmaktadır. Söz konusu sorunun, atıkların yeniden değerlendirilmesi yoluyla giderilmesinin sınırlı olan doğal kaynakların üstündeki insan baskısının azalmasına olumlu katkı yapacağı çeşitli çalışmalarda ortaya konulmuştur. Atık mermerin başta inşaat olmak üzere aralarında tarımında olduğu çeşitli kullanımlarına yönelik çalışmalar yapılmıştır. Ancak estetik açıdan çok geniş renk yelpazesine sahip atık mermerin görsel kullanımı şu anki bilgimiz dâhilinde çalışılmamış bir konu olarak görülmektedir. Atık mermerlerin farklı bir yaklaşımla değerlendirilmesini öngören çalışma Adıyaman ilinde çokça açığa çıkan atık mermerden mozaik eserler üretiminin yapılmasını kapsamaktadır. Adıyaman ili ve çevresi Antik dönem krallıklarından olan Kommagene Krallığı ve Roma kültüründen kaynaklanan zengin antik mozaikleriyle tanınan bir bölgedir. Bu nedenle üretimi gerçekleştirilen mozaikler antik dönem mozaik tasarımlarından ilham alınarak günümüz katı atıklarıyla yeniden üretilmiş, yerel atıklardan elde edilemeyen renkler için inşaat atığı olarak açığa çıkan cam mozaikler kullanılmıştır. Bir yıl süren ayrıntılı desen ve üretim boyutlarında gerçekleştirilen denemeler sonucunda bölgedeki atık mermerlerin renk sınırlamaları nedeniyle yakın illerdeki farklı renklere sahip mermer atıklarııın da kullanılabileceği saptanmıştır. Sonuçta bu çalışmada doğal ve endüstriyel atıkların kültürel mirası temsil edecek mozaik üretiminde kullanılmasıyla bölgede işsizliğin yaygın olduğu kadınlara yönelik özellikle turizmi ve inşaat sektörünü hedefleyen yeni ve estetik bir iş alanı önerisi geliştirilmiştir.

Anahtar Kelimeler: Mermer atığı, Mozaik, Kültürel miras, İstihdam, Cinsiyet eşitliği, Adıyaman.

\section{An Aesthetic Solution to Solid Waste Use: Ancient Mosaic Production from Marble Waste in Adıyaman Province}

\begin{abstract}
Today, as a result of the use of natural resources on a global scale, a serious amount of waste material is produced. In particular, solid wastes such as marble and granite that cannot be biodegradable cause environmental problems. The reuse of these materials should be considered as a solution-oriented approach to prevent environmental pollution as well as adding value to the economy. Turkey is high ranked in marble export globally. As block marble production takes place with an average of 5-10\% efficiency, storage of waste marble causes important environmental problems. It has been demonstrated in various studies that the problem in question will be positively contributed to the reduction of human pressure on natural resources, which is limited by recycling the wastes. Studies have been carried out for various uses of waste marble especially in construction and other areas including agriculture. However, the visual use of waste marble with a wide aesthetic color range is not studied yet to our current knowledge. In this context, the study involves the production of mosaic works made from waste marble, which is widely discarded in Adiyaman province. The province of Adiyaman and its surroundings is a region known for its exquisite antique mosaics originating from the ancient Helenistic Commagene Kingdom and Roman period cultures. Therefore; sample mosaics were inspired by the ancient Roman designs and glass mosaics that were produced as construction waste were used for the colors that could not be obtained from local solid wastes. As a
\end{abstract}

*Sorumlu Yazar: yapraktanriverdi@gmail.com 
result of the experiments carried out in detailed patterns and production dimensions that lasted for a year, it was determined that marble wastes of different colors in the nearby provinces can be used due to the color limitations of the waste marbles in the region. To conclude, in this study, a new and aesthetic business proposal targeting tourism and construction sector was developed for women, where unemployment is common in the region, by using natural and industrial wastes in mosaic production to represent cultural heritage.

Keywords: Marble waste, Mosaic, Cultural heritage, Employment, Gender equality, Adiyaman.

\section{Giriş}

Türkiye jeolojik yapısı nedeniyle taş ocaklarının yaygın dağılım gösterdiği ülkeler arasındadır (Kazancı ve Gürbüz, 2014, s. 19). Söz konusu jeolojik zenginlik aynı zamanda tarih boyunca Anadolu'da taşların mimaride yoğun kullanılmasına neden olmuştur. Renk ve doku ile sağlamlık açısından seçkin bir kayaç olan mermer belki de Anadolu'nun en yaygın kullanılmış olan kayacidır (Bruno ve ark. 2012, s. 403). Mermer, tarihsel süreçte villalar ve önemli kamu binalarının yanı sıra dönemin heykel, rölyef ve mozaik gibi görselliğin öne çıktığı eserlerinde de yaygın olarak kullanılmıştır. Özellikle Roma İmparatorluğu Döneminde Anadolu'nun çeşitli yerlerinden imparatorluğun farklı bölgelerine mermer gönderildiği bilinmektedir (Perkins, 1951 , s. 97). Bu olgu günümüzde de devam etmekte olup, Türkiye dünyaya büyük hacimli blok mermer ihraç etmeye devam etmektedir. Ancak üretim \%5-10 arasında verimlilikle gerçekleştiğinden bu mermerlerin üretimi nedeniyle ülkede yüksek düzeyde atık mermer ortaya çıkmaktadır (Çelik ve Sabah, 2008, s. 109).

Atık mermerin kullanımına yönelik birçok araştırma yapılmış ve başta inşaat olmak üzere aralarında tarımın da olduğu birçok alanda kullanılabilirliği ortaya konmuştur (Gencel ve ark. 2012, s. 62; Büyük ve ark. 2017, s. 167). Ancak mevcut kullanımlardan hiçbiri mermer katı atıklarının renk ve dokusundan kaynaklanan estetik özelliklerini değerlendirmemiştir. Mermer jeolojik oluşum özelliklerine bağlı olarak farklı renk ve doku özellikleri göstermektedir. Renk oluşumunda kayaçtaki safsızlıklar olarak tanımlanan demir oksitler sarı, sarımsı veya kırmızı renkleri verirken manganez oksitler ve karbon içerikleri koyu mavimsi, mor veya siyah renkteki mermerleri oluşturmaktadır (Garcia-Valles ve ark. 2000: s. 222). Metamorfizma nedeniyle mermer kütleleri çeşitli yapısal değişimler geçirerek fiziksel ve kimyasal değişim göstermektedir. Yapısal kusurlar olarak adlandırılan bu değişimler damarlı ve değişik kristal boyutlu kayaç oluşumuna yol açar. $\mathrm{Bu}$ da mermere dokusal ve morfolojik özgünlük kazandırır (Gökay ve Gündoğdu, 2008, s. 1343). Türkiye bu açıdan geniş bir renk ve doku özelliklerindeki mermerlere sahiptir (Şekil 1).

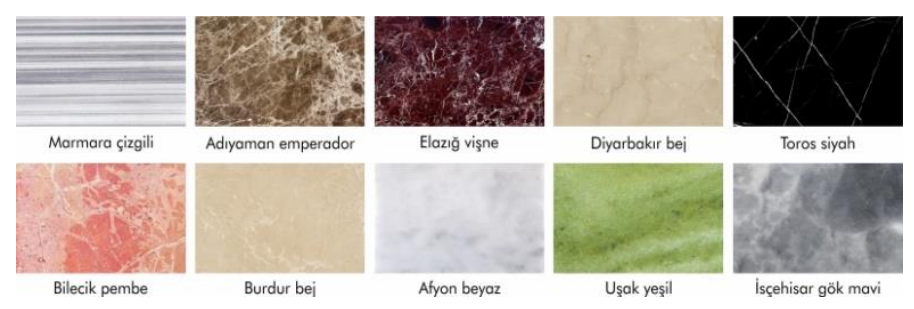

Şekil 1. Türkiye'deki Bazı Mermer Renkleri

Anadolu mermerlerindeki renk ve doku çeşitliliği Anadolu kültürel mirasının önemli bir kısmını oluşturan estetik mozaik koleksiyonlarının üretilmesine olanak sağlamıştır. Doğal taşların kesilmesiyle (tessera) üretilen çok renkli ve hassas işçilikli
Zeugma (Gaziantep), Antioch (Hatay), ve Edessa (Şanlıurfa) mozaikleri bunların başlıca örneklerindendir (Tanrıverdi ve ark. 2018, s. 406). Örneğin Zeugma mozaik müzesindeki Dionysos büst mozaiğinde baskın düzeyde yerel doğal kayaçların kullanımı yanı sıra odak noktası olan diadem (taç) ve thyrsusta (kozalak süslü değnek) mavi-yeşil tonlarında cam mozaik kullanımı hassas ve detaylı işçiliğin göstergeleridir (Şekil 2). Zeugma'yı da içine alan Antik Kommagene krallığında ve sonrası Roma yerleşimlerinde büyük olasılıkla Fırat Nehri ve yerel kökenli kayaçların kullanımı ile geniş renk skalasına sahip çok sayıda mozaik üretilmiştir (Abadie-Reynal, 2002, s. 750).

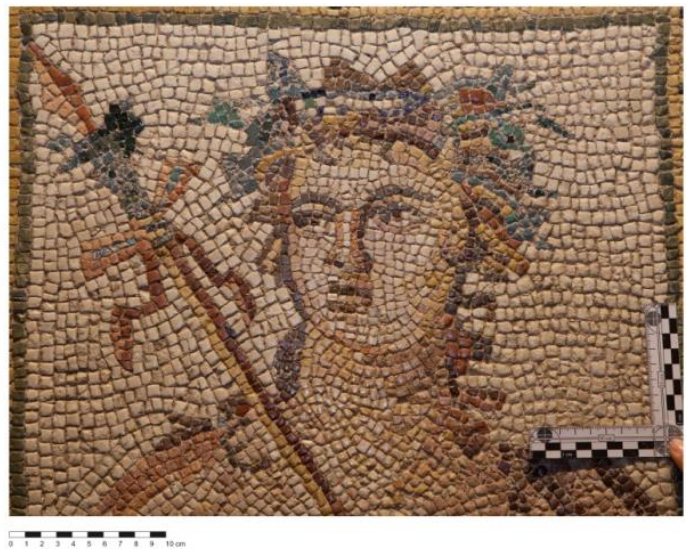

\section{Şekil 2. Dionysos Büst Mozaiği, Gaziantep Zeugma Mozaik} Müzesi

Adıyaman ili Zeugma gibi Kommagene krallığı bölgesinde ve Firat Nehri'nin kıyısında yer almaktadır. Paleolitik çağdan günümüze kesintisiz yerleşim bölgesi olduğundan kutsal tapınaklardan kerpiç evlere sayısız kültürel yapıya sahiptir. Bunlar arasında yerel kayaçlar kullanılarak üretildiği düşünülen mozaikler önemli yer tutmaktadır. Kapsamlı kazılar sayılı olsa da, bölgenin tarihsel zenginliği ulusal ve uluslararası turizm açısından büyük bir potansiyele sahiptir. Nemrut Dağı, Arsameia ören yeri, Perre (Pirin) nekropolü vb. yoğun ilgi çeken arkeolojik alanlardır. Adıyaman'da antik dönemde refahın göstergesi sayılabilecek ve sınırlı sayıdaki kazılarda yüzeye çıkan mozaiklerde kullanılan taşlar (Şekil 3) bölgedeki zengin jeolojiden kaynaklı (Perinçek, 1979, s. 46) taş yataklarına işaret etmektedir. Mozaik yapımında kimi renklerin (mavi) doğal taşlardan sağlanması bunların camdan üretilerek kullanılmasına yol açmıştır. Adıyaman'ının seramik üretimi açısından uzun bir geçmişi olduğundan hemen hemen benzer teknoloji ile üretilen camın da yerel üretiminde yapıldığı ileri sürülebilir. Zeugma kentinde bulunan mozaiklerin bazılarında, Samosata'lı (Eski Samsat) ustaların imzasının bulunması ise bu bölgenin antik çağdaki üretimine ve mozaik atölyelerinin varlığını desteklemektedir (Blömer ve Winter, 2011, s. 245). Bu bölgede antik dönemde yüksek bir değer olan ancak sonrası yüzyıllarda ve günümüzde neredeyse tamamen unutulmuş olan mozaik sanatını yeniden canlandırmak, kentin turizm potansiyeline katkısı yanında, mozaik üretiminin fiziksel olarak ağır işçilik gerektirmemesi günümüzde istihdam sıkıntısı yaşayan 
kadınlarımıza yeni bir gelir kaynağı alanı yaratabilecektir. Çünkü 1990'ların ortasından beri yürütülen Güneydoğu Anadolu Projesi "Kadının Statüsü ve Kalkınma Sürecine katılımını" amaçlamaktadır. $\mathrm{Bu}$ çalışma söz konusu yaklaşıma uygun olduğundan kadınların mozaik üretmesini hedeflemesi açısından karar vericiler için yararlı olacağına inanmaktayız. Sonuçta yoğun olarak katı mermer atıkları kullanılacağı mozaik üretimin yeniden hayata geçirilmesi için bir ön çalışma olan bu araştırma sadece Adıyaman değil arkeolojik açıdan varsıl tüm Güneydoğu Anadolu'da kültürel mirasın yaşatılıp geliştirilmesi, çevre koruma ve kırılgan kesim olan kadınlar için yeni gelir kaynağı yaratması açısından farkındalık yaratacağı düşünülmektedir.

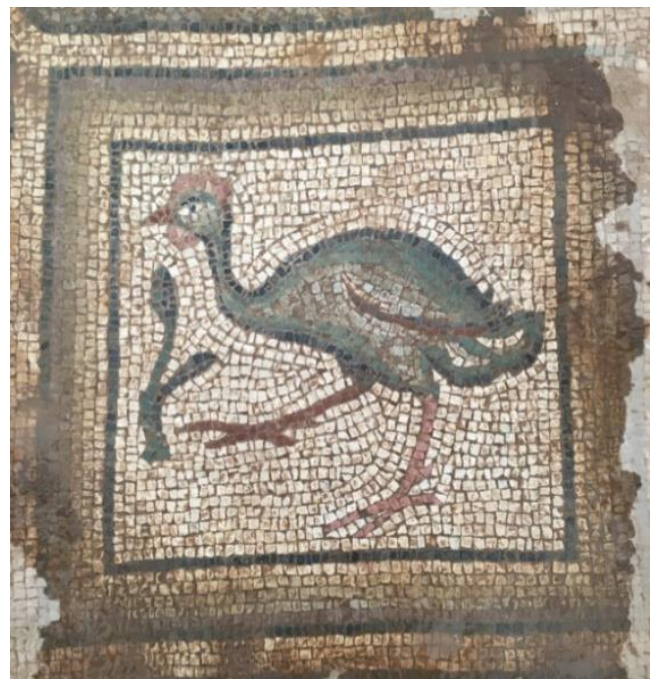

Şekil 3. Adıyaman'daki Perre Antik Kenti Kazısında Çıkarılan Mozaikten Bir Detay

\section{Materyal ve Metot}

\subsection{Materyal}

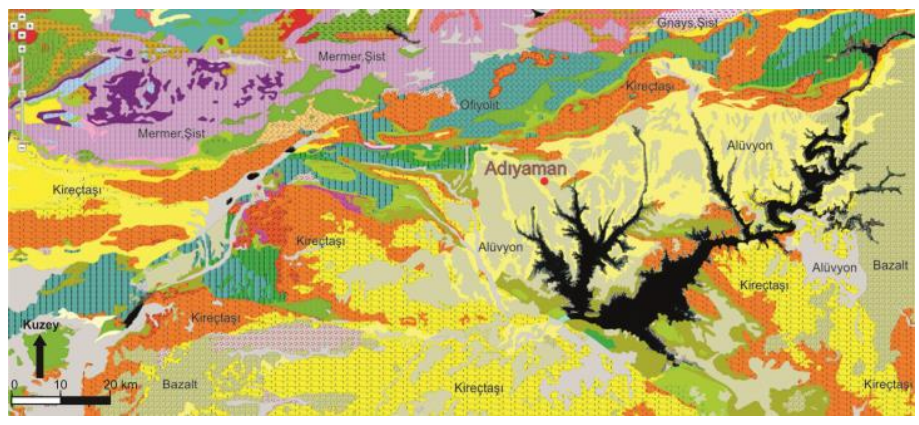

Şekil 4. Adlyaman İli ve Çevresinde Kireçtaşı ve Mermer

Dă̆llımı (http://yerbilimleri.mta.gov.tr/anasayfa.aspx web adresinden değiştirilerek)

Adıyaman ili ve çevresinde kireçtaşı ve mermer yaygın olarak bulunmaktadır (Şahin ve Işık, 2010, s. 129- Şekil 4). Bu nedenle bölgede faaliyet gösteren çok sayıda mermer ocakları bulunmaktadır (Şekil 5). Mermer üretiminde mermerin kesilmesi sırasında makinaların kesme işlemini yapan testerelerin ağzından çıkan mermer atıkları oluşmaktadır. Adıyaman'da yapılan mermer işleme sonucunda oluşan yıllık atık miktarının 90.000 ton olduğu bilinmektedir (Büyük ve ark, 2017, s. 167). Bu atıklar herhangi bir geri kazanım işlemi yapılandan doğrudan doğaya bırakılmaktadır. Mermer üreticileri için sıkıntı yaratan bu mermer atıkları değerlendirmek için öncelikle yerel üreticiler ziyaret edilmiş, elde kesime olanak sağlayacak kalınlıktaki ve farklı renklerdeki mermerler toplanmıştır (Şekil 6). Adıyaman ilinde yaygın olarak bulunan bir mermer türü olan emperadorun açık, orta ve koyu renkli üç farklı çeşidi bulunmaktadır.
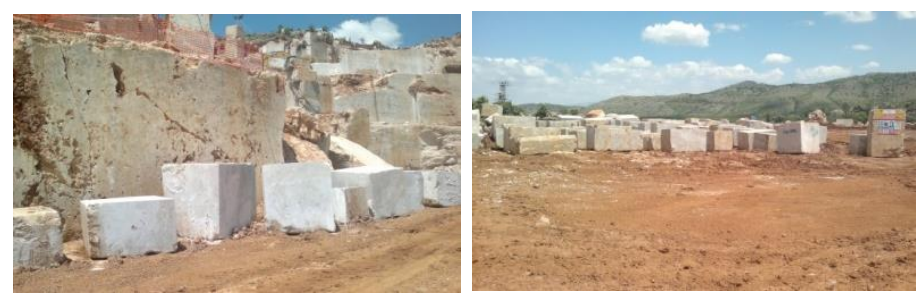

Şekil 5. Adlyaman Bölgesi Arı ve Beden Madencilik Mermer Ocaklarl

Kesime uygun boyutlu mermer atıkları elle toplandıktan sonra, bir renk skalası çıkarılmıştır. Mozaik yapımında gerekebilecek ancak yerel mermer atıklarından elde edilemeyen vişne ve siyah renk grupları başka yörelere ait mermer atıklarından ve bölgeye ait diğer yerel kayaçlardan (siyah ve gri için bazalt, yeşil için ofiyolit vb.) tamamlanmaya çalışılmıştır. Antik dönemden bilindiği üzere, bu bölgede Frrat Nehri'ndeki kayaçlarda eksik olan renkler, zamanında kurulmuş cam atölyelerinde elde edilen cam tesseralarla tamamlanmıştır. Bundan dolayı bu çalışmada doğal taşlardan elde edilemeyen mavi, yeşil ve kırmızıdan oluşan eksik renkler ise inşaat alanlarındaki atık cam mozaik parçaları kullanılarak tamamlanmıştır. Prototip oluşturacak mozaikler, Roma dönemi mozaiklerinden seçilmiştir. Taş kesimlerinin uygunluğunu test etmek için, geometrik ve figüratif desenli mozaikler tercih edilmiştir.
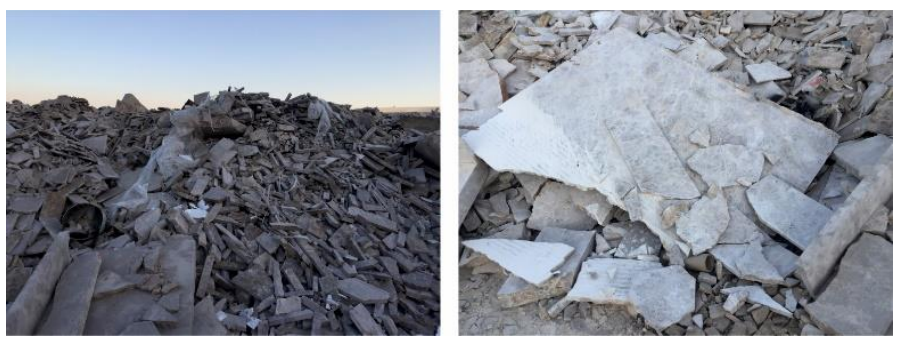

Şekil 6. Üretim Sonrası Açığa Çıkan Atık Mermerler

\subsection{Metot}

Çalışmada mozaik üretimi direkt metot olarak tanımlanan, tesseraların direk yüzey üzerine yapıştırılması ile elle gerçekleştirilmiştir. Deneme üretimi planlanan mozaikler, Anadolu'da mozaik sanatının doruğuna ulaştığı Roma dönemine ait mozaiklerdir. Farklı coğrafyalardaki Roma konutlarında yer alan, uygulanabilir motifler seçilmiştir (Halikarnas, Türkiye; Aya Trias, Sipahi, Kuzey Kıbris; Italica, Sevilla, İspanya vb.). Mozaiklerdeki desen ve figürlerin daha belirgin olması başka bir tanımla incelikli/detaylı çalışmak amacıyla tessera boyutları $1 \mathrm{~cm}$ 'den küçük olacak şekilde ozalit çıktıları alınmıştır. Duralitten oluşan zemin üzerine çıktısı alınan mozaik görseli yapıştırılmıştır. Görsel üzerine plastik bir koruyucu katman gerilmiştir. Daha sonra dayanımı arttırmak için mozaik filesi üzerine tesseralar yapıştırılmıştır. Mozaik üretiminde kullanılacak atık materyalden elde edilen ve en büyüğünün çap1 
$1 \mathrm{~cm}$ olan materyallerin yapıştırılması için su bazlı tutkal kullanılmıştır. Desen ve figürlerin tamamlanması için gerektiğinde materyaller değişik başlı kesiciler ve çekiç kullanılarak kırılmıştır (Şekil 7).
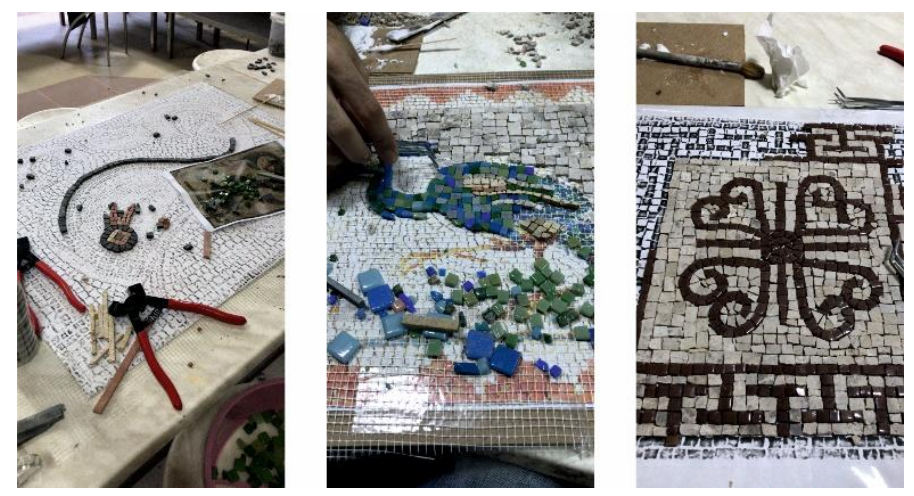

Şekil 7. Roma Dönemi Geometrik ve Figüratif Mozaiklerin Uygulanmast

Mozaik yapımında incelik ve zaman gerektiren olgu taşların/materyalin istenilen şekle uygun boyuta getirilmesi için kırılmasıydı. Bununla birlikte kesici ve kırıcı alet kullanıldığından gerekli iş güvenliği önlemlerin alınmasına özen gösterilmiş eldiven, gözlük ve önlük kullanılmıştır. Gelişigüzel bir kırım istenilen şekilleri vermeyeceği için, bu aşamada gereken işgücü oldukça fazlaydı. Mozaik yapımında bir kişi figür olmayan 10x10 cm'lik bir alanı taş kırmayla birlikte bir buçuk- iki saat arasında tamamlamıştır. Söz konusu bu alanda figür ve desen varsa taş boyutu $0,2 \mathrm{~cm}$ 'de değin küçüldüğünden hazırlama süresi artmıştır. Mozaikler kuruduktan sonra yüzeyi vernikle parlatılıp son haline getirilmiştir.

Eski dönemde mozaikler daha çok zemine veya duvara uygun bir harçla sabitlenirken günümüzde tesseraların kenarlardan kaymasını veya kırılmasını önlemek için bir çerçevede içinde üretilmektedir. Bu çerçeve, mozaiğin boyutuna, şekline ve amaçlanan amacına bağlı olarak ahşap, metal, beton veya istifa gibi çeşitli malzemelerden yapılabilmektedir. $\mathrm{Bu}$ çalışmada ise turizm amaçlı üretim için hafifliği ve doğallığ1 nedeniyle ahşap çerçeve tercih edilmiştir. Örnek üretimde tesseralar orijinaline uygun şekil ve büyüklükte kesilmiştir. Bundan dolayı 10x10 cm'lik figüratif olmayan bir alan için taşların kırılmasıyla birlikte 1-1,5 saat harcanmıştır.

\section{Araştırma Sonuçları ve Tartışma}

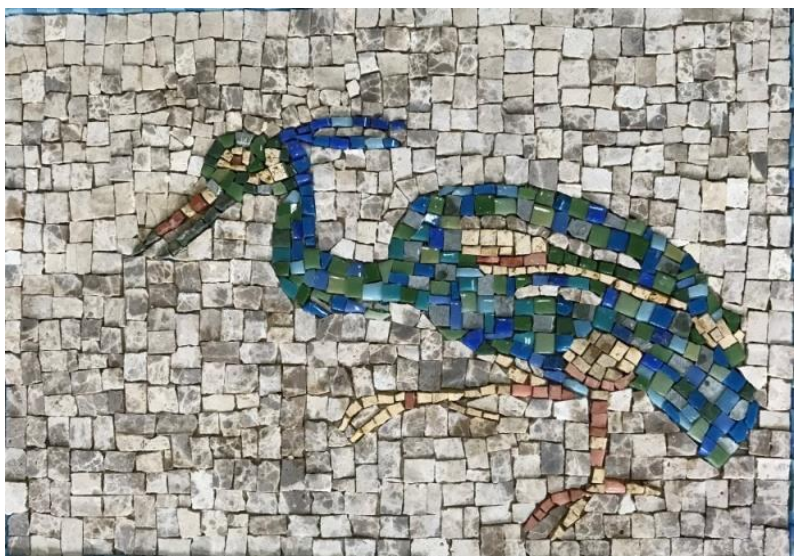

e-ISSN: $2148-2683$
Şekil 8. Roma Dönemi Villa Örneklerinden Seçilen Kuş Motifi Reprodüksiyonu

Çalışmanın gerçekleştiği Adıyaman, yoğun inşaat faaliyetlerinin olduğu gelişmekte olan bir bölgedir. Mozaik üretimi için kullanılan renkler belirlenip uygun renkte taş seçimi ve kırımı yapılarak tesseralar hazırlanmıştır. Renk skalasında eksik olan renkler için, yerel mermer atıkların dışındaki inşaatta kullanım fazlası olan ve başka bir yerde kullanılma olasılığ olmayan ve estetik anlamda (parlaklık, matlık, renk kapsamında) mozaiğe katkı yapan endüstriyel cam mozaiklerin değerlendirilmesine önem gösterilmiştir. Sonraki aşama mozaiğin hangi taş dizilimiyle yapıldığının göz önünde bulundurulmasıdır. Mozaikler tesseraların şekil ve düzenine veya düzensizliğine göre sinıflandırılmaktadır (opus tessellatum, vermiculatum vb.) (Dunbabin ve Dunbabin 1999; King, 2006). Seçilen antik mozaikler, hangi teknikle yapıldıysa özgünlüğüne sadık kalınarak yeniden üretilmiştir. Örneğin kuş figürlü mozaikte (Şekil 8) arka planda opus tessellatum kullanılmışken (bu teknikte figürün çevresinde yaklaşık $4 \mathrm{~mm}$ den büyük tesseralar yatay ve düşey hizalı kullanılır) yunus figürü olan mozaikte (Şekil 9) opus vermiculatum (bu teknikte taşlar figürü bir kontur gibi çevreler ve vurgulamak için bu şekilde devam eder) kullanılmıştır.

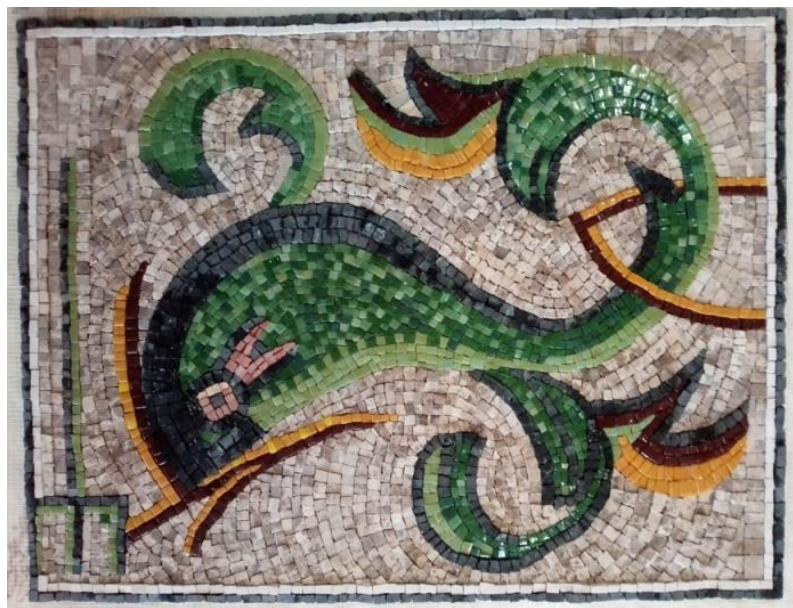

\section{Şekil 9. Halikarnas 'ta Bir Roma Dönemi Evinden Antik Yunus Mozaiğinin Reprodüksiyonu}

Figür içeren kısımlarda işçilik bunun iki katına kadar çıkmıştır. 10x10 cm'lik bir alan için, 2 TL'lik tutkal harcanmıştır. Mozaiğin arkasında kullanılan duralit tercihe bağlıdır (istenirse masa üzerine ozalit çıktı yapıştırılıp, üstüne plastik örtü ve file serilebilir) ürün çerçevelenecekse gereklidir ve $3 \mathrm{~mm} 35 \times 50 \mathrm{~cm}$ ürün yaklaşık 6 TL'dir. $50 \mathrm{~m}^{2}$ mozaik filesi 120 TL'dir, $1 \mathrm{~m}^{2}$ si yaklaşık 2,5 TL'dir. Plastik koruyucu tabaka piyasada $2 \times 25 \mathrm{~m} 110 \mathrm{TL}$ bir mozaik için 2 TL civarıdır. Çerçeve hariç 50x50 cm'lik bir mozaik için yaklaşık 20 TL masraf olacaktır. Taşların \%75'i atık taş olacağından, eksik kalan renklerin satın alınması 20 TL harcama gerektirmektedir. Sonuç olarak antik figür temalı mozaiğin üreticiye maliyetinin yaklaşık 100 TL olduğu hesaplanmıştır. Makalenin kaleme alındığı Nisan 2020 tarihinde $60 \times 100 \mathrm{~cm}$ boyutunda doğal taş kullanılmış bir mozaik detayına göre 1000-3000 TL civarı alıcı bulmaktadır (https://www.dogaldekor.com/tas-mozaik-tablo-ayasofya-camiidt1599). Örnek çalışmamız kapsamında bir kişinin günde 8 saat çalışarak 20x20 cm'lik bir alanı, 10-12 günde ise 60x100 cm'lik bir mozaiği tamamlayabileceği ortaya konulmuştur. Ayda bu boyutta adedi 150 ile $300 \mathrm{TL}$ masrafla 3 mozaik üretilebileceği 
ve bunların satışından 3000-9000 TL ciro elde edilebileceği düşünülmektedir.

\section{Sonuç}

Doğal kaynaklar üzerine olan baskının azaltılmasında atıkların yeniden kullanımı gün geçtikçe önem kazanmaktadır. Güneydoğu Anadolu Bölgesinde yer alan Adıyaman jeolojik oluşumu nedeniyle kireçtaşı ve mermer kayaçlarının yoğun olduğu bir bölgedir. Bu nedenle son yıllarda mermer ocaklarının sayısı artmış ve yüksek düzeyde üretim gerçekleşmiştir. Ancak mermer blok üretiminde \%5-10 arası olan verimlilik nedeniyle ciddi miktarda atık ortaya çıkmaktadır. Adıyaman'da yılda 90.000 ton atığın çıktığı bilinmektedir. Mermer atığı Türkiye ve Dünya'da inşaat ve tarım sektöründe kullanılmaktadır ancak bu çalışmada mermerin ilk kez morfolojik özellikleri dikkate alınarak mozaik üretiminde değerlendirilmesi öngörülmüştür. Mozaik üretiminde ise bölgenin kültürel mirası dikkate alınarak antik desenler seçilmiştir. Atık mermerin renk skalası dar olduğundan aralarında yeşil ve siyah olan renkler diğer kayaçlardan, mavi ve kırmızı/bordo ise yine atık bir materyal olan inşaat cam mozaiklerinden alınmıştır. Mozaik desen seçiminde ise Kommagene Krallığı ve Roma İmparatorluğu örnekleri kullanılarak mozaik sanatını yeniden gündeme getirmek, bölgenin kültürel mirasına sahip çıkmayı amaçlanmıştır. Mozaik üretimi hassas işçilik gerektirdiğinden ve çok ağır fiziksel güç istemediğinden bölgede istihdam olanağ 1 bulamamış kırılgan kesim olan kadınların kolaylıkla yapabileceği bir sanatsal çalışma olacağına inanılmaktadır. Piyasada 40x50cm boyutlarında el yapımı mozaikler çalışmamız yazılırken 1000TL civarında olduğu görülmüştür. Bir kişinin bu boyutta bir ürünü günde 8 saat çalışarak 5-6 günde tamamlayabileceği görülmüştür. Burada dikkat edilmesi gereken konu piyasada satılan seramikler her ne kadar el emeği ile üretilmiş olsalar da kullanılan tesseraların hazır materyal olarak alınıp kullanılmasıdır. $\mathrm{Bu}$ çalışmada üretilen mozaiklerin minimum \%75'i elde kırılan taşlarla antik çağlardaki üretim teknikleri kullanılarak üretilmiş olması pazar şansını arttıran bir olgu olacaktır. Sonuçta birçok alanda değerlendirilmiş mermer atıkları, renk ve doku özellikleri göz önünde bulundurularak estetik anlamda değerlenecek, kullanım alanı olmadığı düşünülen atıklar sanatsal bir etkinlikte kullanılmış olacaktır. Unutulmaya yüz tutan mozaik sanatı tekrar gündeme gelerek, bölgenin kültürel mirası ileriki nesillere aktarılabilecektir. Bunlarla birlikte olarak istihdam olanağı bulamamış kadınlar için alternatif bir gelir kaynağı yaratılmış olacaktır. Depolama açısından sıkıntı yaratmayacak mermer atı ve kırım malzemeleri, evde bir odanın içerisinde tutulup, uygulama yapılabileceğinden, kadınların evlerinden rahatlıkla çalışabilecekleri bir alan oluşacaktır.

\section{Teşekkür}

$\mathrm{Bu}$ çalışma Adıyaman Üniversitesi Bilimsel Araştırma Proje Birimi tarafindan TEBMYOMAP/2017-0001 nolu proje ile desteklenmiştir.

\section{Kaynakça}

Abadie-Reynal, C. (2002). Les maisons à décors mosaïqués de Zeugma. Comptes rendus des séances de l'Académie des Inscriptions et Belles-Lettres, 146(2), 743-771.
Blömer, M. \& Winter, E. (2011). Commagene: The Land of Gods between Taurus and Euphrates. İstanbul: Homer Yayınları

Büyük, G., Yarşi, G., Akça, E. \& Bayram, C. A. (2017). Sera Koşullarında Mermer Tozunun Karbondioksit Kaynağı ve Yetiştirme Ortamı Olarak Kullanılması. KSÜ Doğa Bilimleri Dergisi, 20(2), 167-174.

Bruno, M., Elçi, H., Yavuz, A. B. \& Attanasio, D. (2012). Unknown ancient marble quarries of western Asia Minor. In Interdisciplinary studies on ancient stone: Proceedings of the IXth ASMOSIA international conference (pp. 562-72). Tarragona: ICAC.

Celik, M. Y. \& Sabah, E. (2008). Geological and technical characterisation of Iscehisar (Afyon-Turkey) marble deposits and the impact of marble waste on environmental pollution. Journal of environmental management, 87(1), 106-116.

Dunbabin, K. \& Dunbabin, K. M. (1999). Mosaics of the Greek and Roman world. Cambridge University Press.

Garcia-Valles, M., Urzì, C., De Leo, F., Salamone, P. \& Vendrell-Saz, M. (2000). Biological weathering and mineral deposits of the Belevi marble quarry (Ephesus, Turkey). International biodeterioration \& biodegradation, 46(3), 221-227.

Gencel, O., Ozel, C., Koksal, F., Erdogmus, E., MartínezBarrera, G. \& Brostow, W. (2012). Properties of concrete paving blocks made with waste marble. Journal of Cleaner Production, 21(1), 62-70.

Gökay, M. K. \& Gundogdu, I. B. (2008). Color identification of some Turkish marbles. Construction and Building Materials, 22(7), 1342-1349.

Kazanc1, N. \& Gürbüz, A. (2014). Jeolojik Miras Nitelikli Türkiye Doğal Taşları. Türkiye Jeoloji Bülteni, 57 (1) , 1944.

King, S. (2006). Mosaic techniques \& traditions: projects \& designs from around the world. Sterling Publishing Company, Inc..

Perinçek, D. (1979). Geological investigation of the ÇelikhanSincik-Koçali area (Adıyaman province). İst. Üni. Fen Fak. Mecmuası, Seri B, 44, 127-147.

Perkins, J. W. (1951). Tripolitania and the marble trade. The journal of roman studies, 41(1-2), 89-104.

Şahin, Ö. \& Işik, V. (2010). Çelikhan (Adıyaman) Civarında Yüzeyleyen Metamorfik ve Magmatik Kayaların Petrolojisi. Geological Bulletin of Turkey, 53(2-3).

Tanrıverdi, Y., Akşit, İ., Akça, E., Elias-Ozkan, S. \& Dolaş, O. (2018). Adıyaman çevresindeki antik mozaiklerin arkeometri yaklaşımıyla tanımlanması. Z. Ö. Biçer (Der.) Mimarlık, Planlama, Tasarım Araştırmaları içinde (405418). Ankara: Nobel Akademik Yayıncılık 